\title{
AN ECONOMIC ANALYSIS OF REWIND, PREMIUM, AND STANDARD EFFICIENCY VERTICAL HOLLOW SHAFT MOTORS FOR IRRIGATION
}

\author{
C. G. Henry, K. B. Watkins, R. U. Mane, G. L. Stark
}

\begin{abstract}
Vertical hollow shaft motors are commonly used for vertical turbine pumps for irrigation. They are a specialty motor which has been exempt from the Department of Energy (DOE) requirement for improved energy efficiency. We evaluated the payback and net present value (NPV) of standard efficiency, energy efficient, and premium efficiency motors for motor sizes used in irrigation. For motor sizes between 22 and $56 \mathrm{~kW}$ (30 and $75 \mathrm{hp})$, the NPV and payback analysis indicated that premium efficient motors are more advantageous than standard efficiency. In motor sizes greater than $75 \mathrm{~kW}$ (100 hp) standard efficient motors are more cost effective than replacing a motor with a premium efficiency motor. When considering a repair or rewind of a motor, the result is highly dependent on the quality, and the resulting efficiency expected after the repair. If a repaired motor nameplate efficiency could be attained after rewinding and repair, then rewinding is most cost effective. However, if original nameplate efficiency is not attained, then it may be more cost effective to purchase a premium efficiency motor over rewinding. New DOE requirements may be advantageous for irrigators even though capital costs will be higher for new motors.
\end{abstract}

Keywords. Motor rewind, Net present value (NPV), Payback period, Premium efficiency motor.

A rkansas is the third largest irrigated state (5.0 million acres) in the United States after Nebraska (8.3 million acres) and California (7.5 million acres) (USDA, 2012). As per Arkansas Natural Resources Commission (2014) about $70 \%$ of water demand in Arkansas is supplied using ground water with $80 \%$ of the water used to irrigate field crops which involves the use of electric or diesel pumps. The largest category of irrigation expense for producers in these states is energy cost associated with pumping of water from surface and subsurface water resources. Although, these costs may not be a major expense, there can be some additional cost savings if more energy efficient electric motors are used. To add further, fail-

(c) (1) $\odot$ The authors have paid for open access for this article. This BY NG ND work is licensed under a Creative Commons AttributionNonCommercial-NoDerivatives 4.0 International License https://creative commons.org/licenses/by-nc-nd/4.0/.

Submitted for review in September 2018 as manuscript number NRES 13107; approved for publication as a Research Article by the Natural Resources \& Environmental Systems Community of ASABE in November 2019.

The authors are Christopher G. Henry, Associate Professor, Biological \& Agricultural Engineering, Kenton B. Watkins, Professor, Agricultural Economics, and Ranjitsinh U. Mane, Program Associate, University of Arkansas, Rice Research and Extension Center, Stuttgart, Arkansas; and Gregory L. Stark, Assistant Professor of Practice, Department of Biological and Agricultural Engineering, Texas A\&M University, College Station, Texas. Corresponding author: Christopher Henry, Rice Research and Extension Center 2900 Hwy 130 E, Stuttgart, AR 72160; phone: 870-673-2661; e-mail: cghenry@uark.edu. ure of an electric motor during the peak crop production season can be a huge financial expense and can cause loss of crop value.

As per United States Department of Agriculture (USDA) 2012 Agriculture Census Survey, Arkansas has 4,070 farms with 54,233 pumps operating to irrigate about 5 million acres of crop land. To be specific, there are on average 13 pumps per farm, the largest concentration of pumps per farm in the United States. The approximate energy efficiency of an electric motor is the highest ranging from $50 \%$ to $99 \%$ followed by diesel motors at $40 \%$ and gasoline motors at $25 \%$ (Gustafson and Morgan, 2004). McDougall (2015) found irrigation pumps operated at 1300 hours per year in his study of irrigation pumps and about half of the pumps in Arkansas were diesel and the other electric. Based on this information there is a potential for considerable energy savings if one were to invest in a premium efficiency motor, which is the most energy efficient motor used in wells and re-lift irrigation systems. However, investing in a premium efficiency motor is an expensive proposition given the initial high cost of investment, but there can be other options such as a rewinding of an existing motor that has better efficiency with a reasonable cost for the producer.

Therefore, investment in a premium efficiency motor or a rewind of the existing motor is an important decision that row crop producers need to make for additional financial savings. The authors could not find any studies that explore the potential financial savings an irrigator could realize with respect to use of a premium efficiency motor over a rewind/rebuilt motor. This article compares cost savings for a 
producer with a National Electrical Manufacturers Associate (NEMA) premium ${ }^{\circledR}$ efficiency motor, energy efficient motor and rewound motor as reported by NEMA. We quantify the value of energy savings associated with the most efficient motor over the motor's life.

\section{NeEd FOR A PREMIUM EFFICIENCY MOTOR}

There has been an increased use of electric-powered irrigation pumps by farmers and irrigation districts in Arkansas because of the increased cost of diesel fuel. However, the ability to convert to a different energy source is dependent on access to an alternative energy source. Infrastructure development and an increasing cost difference in energy costs between diesel and electricity have promoted more electric motor purchases in recent history. Data from the Rice Research Verification Program reports the cost of operating an electric pump is the lowest followed by natural gas and diesel pumps (Henry et al., 2016). As discussed earlier, the electric motors are efficient with respect to conversion of electric energy to mechanical energy. The standard efficiency motors manufactured since 1950's had lower efficiency (overall average $84 \%$ ) (Nadel et al., 2002, Sahni et al., 2010). In response to energy efficiency concerns in the 1970's, manufacturers voluntarily offered "energy efficiency" models. Energy efficiency models had improved efficiency (overall average of about $87.5 \%$ ) compared to earlier models (Nadel et al., 2002, Sahni et al., 2010). The use of more copper and steel in the manufacturing process (Lowe et al., 2010) was responsible for the improved efficiency gains.

In 2001, a specification was developed by the Consortium of Energy Efficiency (CEE) and the Energy Star label initiative of the U.S. Environmental Protection Agency (EPA). The NEMA developed NEMA Premium specification for what is known as the Premium Efficiency Motor (Sahni et al., 2010). The premium efficiency motor is the most efficient motor with a minimum average efficiency of $90.2 \%$ (this varies by vintage, manufacture, and motor size). Although the efficiency standards have increased over the past few decades, the acceptance and use of more efficient motors in irrigation has not been well accepted. This is likely due to the lack of awareness of the cost recovery potential of the increased capital cost of a premium efficiency motor. The operating cost of the motor for its entire life time is $97 \%$ to $98 \%$, whereas cost of purchase is only $2 \%$ to $3 \%$ of the total cost (Lowe et al., 2010). A 2010 study by Lowe et al. for the Center on Globalization, Governance \& Competitiveness (CGGC) suggests there are many organizational, economic, technical, and value chain barriers to adoption of high efficiency motors. Thus low adoption of higher efficiency motors is not unique to agriculture.

\section{The Vertical Hollow Shaft Motor}

Vertical hollow shaft motors (VHS) became available in the early 1920's in response to meeting the needs of the vertical turbine pump industry (NIDEC, 2015). The vertical hollow shaft motor is considered a specialty motor and has not historically been subject to the federal motor efficiency requirements until June 2016. The VHS motor is physically different from all other motors in that the motor is designed to accommodate the shaft of a vertical turbine pump through the center of the motor. The shaft is then coupled to the top of the motor and supported by a high thrust bearing. This threaded coupler allows for the proper adjustment of the impeller with the bowl and for shaft stretch (NIDEC, 2013). There is no mechanical loss between the transfer of power between the motor and pump in right angle gear drives since the impeller is essentially directly coupled to the motor rotor. VHS motors can support the weight of the impeller, water column, and shaft and have high thrust bearings to support this load that are typically oil lubricated. A second bearing, typically grease lubricated, is primarily used to maintain shaft alignment. Typical VHS motors used in irrigation are weather protected for outdoor use and exclude rain and snow, but are not weatherproof or totally enclosed. They are fan cooled to dissipate the heat load from the motor and upper bearing. In well applications, they include a non-reverse ratchet to prevent the reversal of threads on the shaft, however in surface water pumps such as mixed flow and axial propeller pumps, this can be removed to allow the pump to spin in reverse to flush the bowl and intake structure using the small amount of water remaining in the column after stopping the pump.

Title III of the Energy Policy and Conservation Act of 1975 established provisions to improve energy efficiency for a certain group of electric motors not previously regulated by existing conservation standards. On 28 July 2014 the rule went into effect and compliance was required by manufactures on 1 June 2016 (US DOE, 2016). The updated standards did not apply to submersible electric motors or inverteronly electric motors. This new rule did apply to VHS motors and required a new minimum nominal efficiency nameplate rating. Because of this rule, standard efficient motors will no longer be available or manufactured in the United States, thus irrigators will be faced with three options, source old inventory standard efficiency motors, rewind or repair their existing motors, or purchase a new premium efficiency motor. Motor manufacturers appear to have developed two options, a full speed motor and a motor that is designed for use with an inverter (also known as variable frequency drive). Previously, most NEMA premium efficiency motors were suitable for inverter use. Inverter rated motors typically have several features or materials that allow them to operate with less inverter-induced damage. Inverter rated motors may have insulated bearings, grounding rings, better heat dissipation, and a higher quality of insulation and wire. In the future only two types of motors are expected to be available after current inventories of standard efficiency motors are depleted, essentially a premium efficiency rated motor, and a model with the same efficiency that is inverter duty rated (NIDEC, 2015).

\section{MOTOR REWINDING AND REPAIR}

Nadel et al., (2002) reported that in general, old motors are repaired approximately 2.5 times more often than new motors. On average, motors are repaired every 5 to 7 years and may be repaired 4 to 6 times before they are permanently replaced. Rewinding of electric motors is a common, comprehensive, complex, and a precision process that involves several steps which can bring the motor to as good as new 
condition, but many rewind motor professionals do not follow procedures or precision and impact the efficiency of the rewind motor (Sahni et al., 2010). A seminal study by Montgomery (1989) listed several different core testing methods such as load test, no load test, and ring test to estimate the quality of rewind with estimated energy saving for each type of energy loss. The study used General Electric (GE) motors and was based on one of several different studies on loss of efficiency due to low quality rewinds. It was estimated, in theory, that a $50 \mathrm{hp}$ drip proof motor with $3600 \mathrm{rpm}$ with core losses of $50 \%$ to $200 \%$ in increments of 50's would increase electricity consumption from $515 \mathrm{~W}$ to more than 2000 W. Similarly, there would be an increase in annual cost of operation from \$271 to more than \$1000. Montgomery emphasized that core loss was a major culprit for loss of efficiency and GE had found an average reduction of core loss of $32 \%$ with a variation of 0 to $400 \%$. A core loss of $20 \%$ represents a reduction in nominal efficiency of $2 \%$. Motors with very high core losses or damaged cores can still operate for long periods of time without failure albeit with high operating costs. So it should be emphasized that motor operation is not a measure of the quality of a rewind.

A more recent study by Saidur et al. (2009) on end users' savings in Malaysia for industrial motors concluded that high-efficiency motors have higher savings (local currency per year) at higher loads $(50,75$, and 100). They also reported a lower payback period for a high-efficient motor at $75 \%$ and $100 \%$ load. As per the McCoy and Douglass (2014) report prepared for Department of Energy (DOE) on Premium Efficiency Motor Selection and Application Guide, an investment in a premium efficiency motor or rewinding a failed standard or energy efficient motor depends on several different factors and loss of efficiency was one of the listed factors.

The MotorsMaster+ tool of the Department of Energy is the best method to evaluate investment in a premium efficiency motor over other motors, but the above mentioned tools do not estimate any saving on a quality of rewind motor that is as good as new and MotorsMaster+ tool does not include vertical hollow shaft motor data in the database.

The Electrical Apparatus Service Association (EASA, 2015) publishes standards on the recommended practice of the repair of rotating electrical apparatus (ANSI/EASA AR100-2015). This standard outlines the inspection, cleaning, repair, rewinding, testing, and safety practices for rewinding and rebuilding electric motors. These standards are based on a study on the loss of efficiency from rewinding and repairing motors (EASA, 2003). This study reports a loss of $0.4 \%$ to $0.6 \%$ on low voltage motors when no specific controls on stripping and a rewind process with a burnout temperature of $350^{\circ} \mathrm{C}$. The laminated core, stator winding, and rotor account for as much as $75 \%$ of the total losses for the motors in the study. The most important repair practices for maintaining motor efficiency were reported to be the burnout process (too low of temperature leads to damage to lamination, too high reduces efficiency), coil removal and preparation, wire size, mean turn length, winding resistance, bearing and windage. Core testing of the core before and after is the best safeguard against the burnout problems. In lieu of load testing, they reported three areas to check for the biggest loss components; core testing before and after burnout, accurate resistance measurement to verify changes in copper losses, and ensuring that rotor losses remain unchanged.

The Department of Energy, Energy Efficiency and Renewable Energy (EERE) case study reported that there is a decrease in efficiency of a rewind motor by $1 \%$ for less than $40 \mathrm{hp}$ and $0.5 \%$ for more than $40 \mathrm{hp}$ rewind motors (EASA, 2003; Sahni et al., 2010). Sahni et al. (2010) summarized previous studies that estimated losses in efficiency for different rewind motors.

\section{OBJECTIVE}

The objective of this article is to compare the Net Present Value (NPV) and Payback Period (PP) of a premium efficiency motor compared to an energy efficient, standard efficiency motor and repairing or rewinding VHS motors used in irrigation pumping plants. Additionally, we wanted to explore the impact of the new DOE energy efficiency rule to determine if the rule created benefit or unnecessary cost to the irrigation industry.

\section{DATA AND METHODOLOGY}

There are several manufactures of VHS motors and retail prices differ greatly. A common brand of motor for the region is US motors. The retail price of standard, energy efficient, and premium efficiency VHS motors for 7-149 kW (10 to $200 \mathrm{hp}$ ) was used for this analysis using the 2014 sales year for US motors/NIDEC (NIDEC, 2013) Catalog (table 2). The cost of rewinds are authors estimates which are discussed in detail in a later section. The cost of electricity is derived from Arkansas Crop Enterprise Budgets and is assumed to be constant for the life of a motor. We assumed a constant electricity price since electricity prices adjusted for inflation have been relatively stable over time in Arkansas since 2000. Installation costs were not included in the analysis. The expected motor life reported by (NIDEC, 2013) was reported to be 30,000 hours and the annual hours of operation were assumed to be 1300 hours (McDougall, 2015). This equates to a 23 year motor life. The premium efficient motors have the highest nominal nameplate efficiency followed by the energy efficient, standard efficient, and a range of rewind losses that an irrigator could expect (fig. 1). Standard efficiency is defined as the efficiency of a new 2014 standard efficiency NIDEC/US motor. This is an important benchmark, because motor efficiencies are different between brands and have changed over time. Thus, irrigators with older motors that are considering rewinding versus a new motor should account for the reduced efficiency in the new rewound motor.

An $85 \%$ nameplate motor load was assumed. Efficiency loss from rewinding is difficult to quantify and we found that the studies reported a wide range of efficiency loss that may result from rewinding. To address the wide range of efficiency losses reported in the literature we assumed the following range of $0.5 \%$ to $5 \%$ loss of nameplate motor efficiency. It is thought that this range is reasonable, as the literature is very conflicted as to what is a reasonable range 
to expect, and so much is based on the quality of work that is obtained from a rewind shop in the agricultural community. Should, in the future, a study better quantify efficiency losses from VHS motors, it is hoped that this work would still be useful. Thus, we reduced the nameplate efficiency $0.5 \%, 1 \%, 2 \%, 3 \%, 4 \%$, and $5 \%$ to calculate the efficiency. For example, a motor with a $90 \%$ nameplate efficiency and a $1 \%$ rewind loss has a, $90 \% \times 1 \%$ loss $=0.09$ loss, so the efficiency after rewinding is $90-0.09=89.1 \%$.

For irrigators deciding between purchasing a premium efficient motor and rewinding and rebuilding existing VHS motors, we created a large gradient in the loss of efficiency from rewinding. The literature reports a range of expected loss, which is mainly a result of how much testing may or may not be done to ensure a good rebuild. According to the DOE EASA, 2016 study, even with no control of stripping and rewind with a burnout temperature of $250^{\circ} \mathrm{C}$, they report a loss of between $0.4 \%$ and $0.6 \%$, and some rebuilders could improve efficiency over new by following the recommended practices. However, the Montgomery (1989) study showed losses in the $2 \%$ range and possibly higher mainly as a result of core loss. We represent the EASA (2003) study with the category of "zero loss" and " $0.5 \%$ loss" and the Montgomery (1989) study as $1 \%, 2 \%, 3 \%, 4 \%$, and $5 \%$. If core losses could be as high as suggested by Montgomery (1989) for shops that do no testing, the loss could be as high as the $10 \%$ loss category. Thus, we did a gradient between zero and $10 \%$ loss to show a range of potential losses an irrigator could experience.

\section{MOTOR OPERATING COSTS AND Motor Purchase Costs}

The Annual Operation Cost $(A O C)$ which is a variable cost is calculated by:

$$
\begin{aligned}
A O C= & \left(P_{E} * O P H * N_{H P} * L * 0.746\right) \\
& \div\left(\eta_{\text {motor }} / 100\right)
\end{aligned}
$$

where

$P_{\mathrm{E}} \quad=$ price of energy $(\$ / \mathrm{kWh})$,

$O P H=$ operating hours per year,

$N_{H P}=$ motor horsepower,

$L=$ motor loading, 0.746 is conversion factor to convert power from horsepower to $\mathrm{kWh}$, and

$\eta_{\text {motor }}=$ motor efficiency (\%).

The voltage requirement for motors less than $45 \mathrm{~kW}$ (60 hp) often can operate at either 230 or $460 \mathrm{~V}$. However, motors in range of $45-150 \mathrm{~kW}(60-200 \mathrm{hp})$ operate at $460 \mathrm{~V}$. The AOC of motor by type of horsepower are presented in table 1 . The retail price of new premium efficiency, energy efficient, and standard efficiency motors as well as cost of motor after different qualities of rewind are presented in table 2. Similarly, figure 1 depicts energy efficiency of a new premium efficiency, energy efficient, standard efficiency, and rewound VHS motors.

Literature related to estimating cost of rewinding and repairing VHS motors is limited. Much of the cost data that is available is only applicable to standard motor types. Also, there appears to be a large variation in the quality of rewind in our communication with motor repair shops in eastern Arkansas. So, it is difficult to quantify cost of rewind based on quality of rewind. The cost of rewind was assumed to be $65 \%$ of the cost of the new standard efficiency motor. The value of $60 \%-65 \%$ is believed to be near the breakpoint for motor repair and replacement (Linda Raynes and Tom Bishop EASA, personal communication on motor efficiency and rewinding, July 2016). The method used to estimate cost of motor rewind and rebuild is based on a $65 \%$ assumption. We assume that irrigators will have a standard efficiency

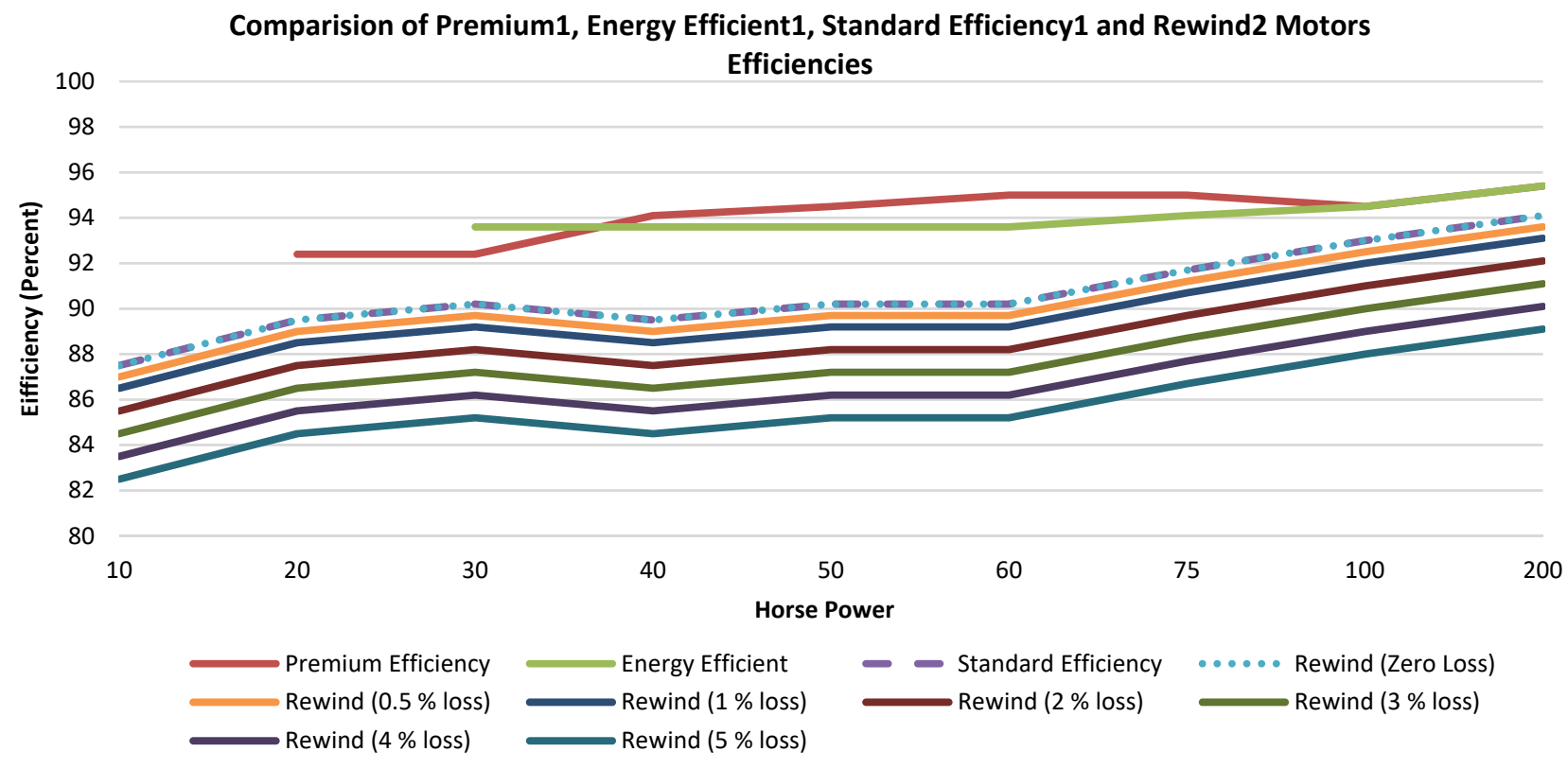

Source: ${ }^{1} \mathrm{NEMA},{ }^{2}$ Authors estimates

Figure 1. Comparison of premium, energy efficient, standard efficiency, and rewind motors efficiencies. 
motor to rewind and must decide between rewinding and repairing versus replacement. The rewind cost relative to new could be as wide as $25-75 \%$ (Greg Stark, Texas A\&M University, personal and written communication about motor efficiency and rewinding, July 2012). No studies could be found that reported the cost to rewind a VHS motors based on quality of rewind.

A blind telephone survey was conducted by the authors in January of 2016 of six motor repair shops known to repair and rewind VHS motors for irrigators in Arkansas. Questions were asked of all repair shops in Arkansas known to repair and rewind VHS motors to confirm repair costs. To validate our assumption, this survey inquired about the costs associated with repairing or rewinding 30, 56, and $75 \mathrm{~kW}(40,75$, and $100 \mathrm{hp})$ motors relative to the cost of new motors. The results from the survey provided a wide cost range of rewind for US Motors (NIDEC) standard efficiency VHS motors, ranging from a high $67 \%$ to a low of $23 \%$ the cost of a new standard efficiency motor. Not every shop included replacing all or part of the high thrust bearing with an OEM replacement, so this cost was a factor in the cost reported. None of the surveyed shops were certified under the EASA Accreditation Program to be following the recommended practice for repair of rotating electrical apparatus, ANSI/EASA AR100-2015. Only one repair shop in Arkansas known to repair VHS motors was listed as a EASA member, thus it seems that other shops in Arkansas are not following the published standards since they do not have access to them. Thus, it is not known if the cost difference is due to labor and material differences or additional costs associated with following the recommended practices, many of which require substantial component testing. From the survey of Arkansas rewind shops, it appears that the majority of electric motors used in agricultural irrigation are repaired and rewound locally. It also seems that limited resources or tools to test the efficiency of a motor after the rewind are in use in these local rural shops. In other words, testing quality of a rewind is a major unknown issue for VHS motors used in irrigation. This is a significant unknown in our analysis, as we cannot clearly correlate the cost of rewinding and rebuilding a VHS motor with the expected efficiency after the motor is rebuilt. Thus, we have provided for a wide range of efficiency expectations for rewound motors and used one value for cost of a rebuild. Based on our research, a study of rewind cost for VHS motors and their related efficiency losses or gains would be needed to better understand if irrigators are being exposed to substantial operating costs due to poor rewinding and rebuilding practices as indicated in Montgomery
(1989). Thus, we settled on the $65 \%$ as our best judgement of what a rewind should cost with everything replaced given the lack of better information and to account for the replacement of the high thrust bearing of good quality.

\section{ECONOMIC EVALUATION OF QUANTIFIED ENERGY SAVINGS For THE Most EfFicient Motor}

In this section, we quantified the value of energy savings associated with the most efficient motor over the motor's life and determined if these quantified energy savings cover the additional cost of purchasing the most efficient motor relative to a cheaper, alternative motor exhibiting lower energy efficiency. We will use two common investment measures, the payback period, and net present value (NPV).

Annual energy savings are calculated as the difference in annual operating costs between the most efficient motor and a less efficient motor. The annual operating costs for each motor is presented by motor type and size in table 1 . Using the data in table 1, annual energy savings (S) for the most efficient motor relative to a less efficient motor is calculated as:

$$
S=O C_{M E}-O C_{L E}
$$

where $O C_{M E}=$ the annual operating cost of the most efficient motor ("Energy Efficient" for $7 \mathrm{~kW}$ motors, "Premium Efficiency" for all other hp ratings), and $O C_{L E}=$ the annual operating cost of a less efficient motor.

Additional cost for the most efficient motor is calculated as the difference in the purchase costs between the most efficient motor and a less efficient motor. The purchase cost for each motor is presented by motor type and horsepower (hp) in table 2. Using the data from table 2, the additional cost (AC) of purchasing the most efficient motor relative to a less efficient motor is calculated as follows:

$$
A C=C_{M E}-C_{L E}
$$

where $C_{M E}=$ the cost of the most efficient motor in table 2, and $C L_{L E}=$ the cost of a less efficient motor.

The NPV method of an investment (also known as the discounted cash flow method) is equal to the sum of the present value (PV) of annual cash inflows from an investment less the initial cost of the investment. In this study, annual energy savings $(S)$ represent annual cash inflows associated with purchasing the most efficient motor instead of the less efficient motor. The NPV formula for this study is:

\begin{tabular}{|c|c|c|c|c|c|c|c|c|c|}
\hline Type of Motor & $\begin{array}{l}10 \mathrm{hp} \\
7 \mathrm{~kW}\end{array}$ & $\begin{array}{c}20 \mathrm{hp} \\
12 \mathrm{~kW}\end{array}$ & $\begin{array}{c}30 \mathrm{hp} \\
22 \mathrm{~kW}\end{array}$ & $\begin{array}{c}40 \mathrm{hp} \\
30 \mathrm{~kW}\end{array}$ & $\begin{array}{c}50 \mathrm{hp} \\
37 \mathrm{~kW}\end{array}$ & $\begin{array}{c}60 \mathrm{hp} \\
45 \mathrm{~kW}\end{array}$ & $\begin{array}{c}75 \mathrm{hp} \\
56 \mathrm{~kW}\end{array}$ & $\begin{array}{l}100 \mathrm{hp} \\
75 \mathrm{~kW}\end{array}$ & $\begin{array}{c}200 \mathrm{hp} \\
149 \mathrm{~kW}\end{array}$ \\
\hline Premium efficiency & $\mathrm{na}^{[\mathrm{a}]}$ & 2,141 & 3,212 & 4,205 & 5,234 & 6,248 & 7,809 & 10,468 & 20,738 \\
\hline Energy efficient & 1,087 & na & 3,171 & 4,227 & 5,284 & 6,341 & 7,884 & 10,468 & 20,738 \\
\hline Standard efficiency & 1,131 & 2,210 & 3,290 & 4,421 & 5,483 & 6,580 & 8,090 & 10,637 & 21,024 \\
\hline Rewind (zero loss) & 1,136 & 2,222 & 3,307 & 4,443 & 5,511 & 6,613 & 8,131 & 10,690 & 21,130 \\
\hline Rewind $(0.5 \%$ loss $)$ & 1,142 & 2,233 & 3,323 & 4,466 & 5,539 & 6,646 & 8,172 & 10,744 & 21,237 \\
\hline Rewind (1\% loss) & 1,154 & 2,256 & 3,357 & 4,511 & 5,595 & 6,714 & 8,256 & 10,854 & 21,453 \\
\hline Rewind ( $2 \%$ loss) & 1,165 & 2,279 & 3,392 & 4,558 & 5,653 & 6,784 & 8,341 & 10,965 & 21,675 \\
\hline Rewind (3\% loss) & 1,178 & 2,303 & 3,427 & 4,605 & 5,712 & 6,854 & 8,428 & 11,080 & 21,900 \\
\hline Rewind ( $4 \%$ loss) & 1,190 & 2,327 & 3,463 & 4,654 & 5,772 & 6,926 & 8,516 & 11,196 & 22,131 \\
\hline Rewind (5\% loss) & 1,256 & 2,456 & 3,656 & 4,912 & 6,093 & 7,311 & 8,989 & 11,818 & 23,360 \\
\hline
\end{tabular}

Table 1. Annual operating cost by type of motor and horsepower in 2014 dollars.

[a] $\mathrm{na}=$ motor type not available for the particular horsepower rating. 
Table 2. Motor purchase cost by type of motor and horsepower in 2014 dollars.

\begin{tabular}{|c|c|c|c|c|c|c|c|c|c|}
\hline Type of Motor & $\begin{array}{l}10 \mathrm{hp} \\
7 \mathrm{~kW}\end{array}$ & $\begin{array}{c}20 \mathrm{hp} \\
12 \mathrm{~kW}\end{array}$ & $\begin{array}{c}30 \mathrm{hp} \\
22 \mathrm{~kW}\end{array}$ & $\begin{array}{c}40 \mathrm{hp} \\
30 \mathrm{~kW}\end{array}$ & $\begin{array}{c}50 \mathrm{hp} \\
37 \mathrm{~kW}\end{array}$ & $\begin{array}{c}60 \mathrm{hp} \\
45 \mathrm{~kW}\end{array}$ & $\begin{array}{c}75 \mathrm{hp} \\
56 \mathrm{~kW}\end{array}$ & $\begin{array}{l}100 \mathrm{hp} \\
75 \mathrm{~kW}\end{array}$ & $\begin{array}{c}200 \mathrm{hp} \\
149 \mathrm{~kW}\end{array}$ \\
\hline Premium efficiency & $\mathrm{na}^{[\mathrm{a}]}$ & 4,542 & 5,709 & 7,296 & 8,317 & 9,866 & 11,505 & 15,399 & 30,810 \\
\hline Energy efficient & 3,364 & na & 5,709 & 6,899 & 7,923 & 9,401 & 11,040 & 14,211 & 28,763 \\
\hline Standard efficiency & 3,751 & 3,732 & 4,685 & 5,502 & 6,526 & 7,540 & 9,178 & 11,596 & 24,221 \\
\hline Rewind (zero loss) & 2,438 & 2,426 & 3,045 & 3,576 & 4,242 & 4,901 & 5,966 & 7,537 & 15,744 \\
\hline Rewind $(0.5 \%$ loss $)$ & 2,438 & 2,426 & 3,045 & 3,576 & 4,242 & 4,901 & 5,966 & 7,537 & 15,744 \\
\hline Rewind (1\% loss) & 2,438 & 2,426 & 3,045 & 3,576 & 4,242 & 4,901 & 5,966 & 7,537 & 15,744 \\
\hline Rewind ( $2 \%$ loss) & 2,438 & 2,426 & 3,045 & 3,576 & 4,242 & 4,901 & 5,966 & 7,537 & 15,744 \\
\hline Rewind (3\% loss) & 2,438 & 2,426 & 3,045 & 3,576 & 4,242 & 4,901 & 5,966 & 7,537 & 15,744 \\
\hline Rewind (4\% loss) & 2,438 & 2,426 & 3,045 & 3,576 & 4,242 & 4,901 & 5,966 & 7,537 & 15,744 \\
\hline Rewind ( $5 \%$ loss) & 2,438 & 2,426 & 3,045 & 3,576 & 4,242 & 4,901 & 5,966 & 7,537 & 15,744 \\
\hline
\end{tabular}

[a] $n a=$ motor type not available for the particular power rating.

$$
N P V=\sum_{y=1}^{23} P V_{y}-A C=\sum_{y=1}^{23} \frac{S}{(1+d)^{y}}-A C
$$

where $y=1$ to 23 years with 23 years being the estimated life of the motor; $P V_{y}=$ the discounted present value of energy savings for the most efficient motor relative to a less efficient motor in year $(y) ; d=$ the discount rate, and $S$ and $A C$ are as defined above. A positive NPV means the cumulative present value of annual energy savings for the most efficient motor over its lifetime would cover the additional costs associated with purchasing the most efficient motor. In this instance, the most efficient motor would be preferred over the less efficient motor. The larger the NPV the better, and the preferred alternative would be one producing the highest NPV. Net present values of energy savings for the most efficient motor relative to less efficient motors are presented in table 3. Net present values are calculated using a discount rate of 0.045 , which represents an intermediate term interest rate charged for farm machinery.

The discounted payback period refers to the amount of time required for the cumulative present value of energy savings to equal the additional cost of the most efficient motor. The discounted payback period differs from the simple payback period, which is calculated as a ratio of the additional cost of the most efficient motor (AC) over the annual energy savings for the additional motor (S). The simple payback period approach assumes annual energy savings remain the same over time and does not account for the time value of money. Thus, the results of the simple payback period are often not consistent with the NPV approach. The discounted payback period does account for the time value of money and is calculated as follows:

$$
D P P=q+\frac{\left|C P V_{q}\right|}{C P V_{q+1}}=q+\frac{\left|\sum_{y=1}^{q} P V_{q}\right|}{\sum_{y=1}^{q+1} P V_{q+1}}
$$

where DPP = the discounted payback period (or the number of years required for cumulative discounted energy savings to pay off the additional cost of the most efficient motor), $q$ $=$ the last period (year) with a negative discounted cumulative present value (or $C P V$ ), $\left|C P V_{q}\right|=$ the absolute value of cumulative present value at time period q, and $C P V_{q+1}=$ the cumulative present value at time period $q+1$ (the year in which the $C P V$ becomes positive). The ratio of $\left|C P V_{q}\right|$ and $C P V_{q+1}$ represents the portion of additional time in $q+1$ (fraction of a year) required for achieving a positive CPV and can take on a value between 0 and 1 . If $D P P$ is less than the target period (the 23 year lifetime of the most efficient motor in this study as reported by the manufacturer), then the most efficient motor is chosen over the cheaper, less efficient motor. If DPP is higher than the life of the motor, then it would not be desirable to purchase a new motor, since the new motor would reach the end of its life before the improved efficiency would pay back the capital cost. Also, a short payback period indicates the discounted cumulative energy savings for the most efficient motor over time would quickly pay for the motor's additional purchase cost. Discounted payback periods for the most efficient motor relative to less efficient motors are presented in table 4 .

\begin{tabular}{|c|c|c|c|c|c|c|c|c|c|}
\hline & $10 \mathrm{hp}$ & $20 \mathrm{hp}$ & $30 \mathrm{hp}$ & $40 \mathrm{hp}$ & $50 \mathrm{hp}$ & $60 \mathrm{hp}$ & $\begin{array}{r}75 \mathrm{hp} \\
56 \mathrm{~kW}\end{array}$ & $100 \mathrm{hp}$ & $200 \mathrm{hp}$ \\
\hline Type of Motor & $7 \mathrm{~kW}$ & $12 \mathrm{~kW}$ & $22 \mathrm{~kW}$ & $30 \mathrm{~kW}$ & $37 \mathrm{~kW}$ & $45 \mathrm{~kW}$ & $56 \mathrm{~kW}$ & $75 \mathrm{~kW}$ & $149 \mathrm{~kW}$ \\
\hline Premium efficiency & $\mathrm{na}^{[\mathrm{a}]}$ & $\mathrm{ME}^{[\mathrm{b}]}$ & $\mathrm{ME}$ & $\mathrm{ME}$ & $\mathrm{ME}$ & $\mathrm{ME}$ & $\mathrm{ME}$ & $\mathrm{ME}$ & $\mathrm{ME}$ \\
\hline Energy efficient & ME & na & -583 & -79 & 318 & 857 & 592 & $-1,188$ & $-2,047$ \\
\hline Standard efficiency & 1,002 & 172 & 84 & 1,264 & 1,739 & 2,378 & 1,649 & $-1,414$ & $-2,536$ \\
\hline Rewind (zero loss) & -311 & $-1,135$ & $-1,556$ & -662 & -545 & -261 & $-1,563$ & $-5,473$ & $-11,013$ \\
\hline Rewind $(0.5 \%$ loss $)$ & -230 & -978 & $-1,322$ & -348 & -155 & 206 & -988 & $-4,717$ & $-9,518$ \\
\hline Rewind ( $1 \%$ loss) & -149 & -819 & $-1,085$ & -30 & 238 & 679 & -407 & $-3,953$ & $-8,009$ \\
\hline Rewind ( $2 \%$ loss) & 16 & -496 & -606 & 614 & 1,038 & 1,638 & 773 & $-2,402$ & $-4,943$ \\
\hline Rewind ( $3 \%$ loss) & 184 & -167 & -116 & 1,272 & 1,854 & 2,618 & 1,977 & -819 & $-1,814$ \\
\hline Rewind (4\% loss) & 356 & 168 & 384 & 1,944 & 2,687 & 3,617 & 3,206 & 797 & 1,381 \\
\hline Rewind (5\% loss) & 531 & 511 & 894 & 2,630 & 3,538 & 4,638 & 4,461 & 2,447 & 4,642 \\
\hline
\end{tabular}

Table 3. Net present values of energy savings for the most efficient motor relative to less efficient motors.

[a] $\mathrm{na}=$ motor type not available for the particular power rating.

[b] $\mathrm{ME}=$ "most efficient" motor in each column. All other less efficient motors are evaluated relative the most efficient motor. The most efficient motor is the "energy efficient" motor type for $7 \mathrm{~kW}$ motors and the "premium efficiency" motor type for all other hp ratings.

Net present value calculations assume an estimated life of 23 years for the most efficient motor and a discount rate of 0.045 . 
Table 4. Discounted payback periods in years for cumulative annual energy savings to fully pay the additional cost of the most efficient motor relative to less efficient motors.

\begin{tabular}{|c|c|c|c|c|c|c|c|c|c|}
\hline Type of Motor & $\begin{array}{l}10 \mathrm{hp} \\
7 \mathrm{~kW}\end{array}$ & $\begin{array}{c}20 \mathrm{hp} \\
12 \mathrm{~kW}\end{array}$ & $\begin{array}{c}30 \mathrm{hp} \\
22 \mathrm{~kW}\end{array}$ & $\begin{array}{c}40 \mathrm{hp} \\
30 \mathrm{~kW}\end{array}$ & $\begin{array}{c}50 \mathrm{hp} \\
37 \mathrm{~kW}\end{array}$ & $\begin{array}{c}60 \mathrm{hp} \\
45 \mathrm{~kW}\end{array}$ & $\begin{array}{c}75 \mathrm{hp} \\
56 \mathrm{~kW}\end{array}$ & $\begin{array}{l}100 \mathrm{hp} \\
75 \mathrm{~kW}\end{array}$ & $\begin{array}{c}200 \mathrm{hp} \\
149 \mathrm{~kW}\end{array}$ \\
\hline Premium efficiency & $\mathrm{na}^{[\mathrm{a}]}$ & $\mathrm{ME}^{[\mathrm{b}]}$ & $\mathrm{ME}$ & $\mathrm{ME}$ & $\mathrm{ME}$ & $\mathrm{ME}$ & $\mathrm{ME}$ & $\mathrm{ME}$ & $\mathrm{ME}$ \\
\hline Energy efficient & $\mathrm{ME}$ & na & $\infty^{[\mathrm{c}]}$ & 36.0 & 9.9 & 5.8 & 7.5 & $\infty$ & $\infty$ \\
\hline Standard efficiency & $0.0^{[\mathrm{d}]}$ & 16.9 & 20.2 & 10.6 & 8.9 & 8.6 & 10.6 & $>60^{[\mathrm{e}]}$ & $>60$ \\
\hline Rewind (zero loss) & $>60$ & $>60$ & $>60$ & 33.8 & 30.2 & 25.3 & 49.5 & $>60$ & $>60$ \\
\hline Rewind $(0.5 \%$ loss $)$ & 42.7 & $>60$ & $>60$ & 27.5 & 24.6 & 21.5 & 33.9 & $>60$ & $>60$ \\
\hline Rewind (1\% loss) & 32.3 & $>60$ & $>60$ & 23.3 & 20.9 & 18.7 & 26.4 & $>60$ & $>60$ \\
\hline Rewind ( $2 \%$ loss) & 22.3 & 40.5 & 39.5 & 18.0 & 16.1 & 14.8 & 18.6 & 56.5 & $>60$ \\
\hline Rewind (3\% loss) & 17.2 & 26.7 & 24.9 & 14.6 & 13.1 & 12.3 & 14.4 & 28.2 & 29.2 \\
\hline Rewind (4\% loss) & 14.0 & 20.2 & 18.5 & 12.3 & 11.0 & 10.4 & 11.7 & 19.6 & 19.9 \\
\hline Rewind (5\% loss) & 11.8 & 16.3 & 14.7 & 10.6 & 9.5 & 9.1 & 9.9 & 15.1 & 15.2 \\
\hline
\end{tabular}

[a] na $=$ motor type not available for the particular power rating.

[b] $\mathrm{ME}=$ "most efficient" motor in each column. All other less efficient motors are evaluated relative the most efficient motor. The most efficient motor is the "energy efficient" motor type for $10 \mathrm{HP}$ motors and the "premium efficiency" motor type for all other HP ratings.

[c] $\infty=$ the annual operating cost of the "most efficient" motor is greater than or equal to the annual operating cost of the "less efficient" motor, indicating no energy savings exist for the "most efficient" motor relative to the "less efficient" motor. The discounted payback period would be infinite in this instance (the additional cost of the "most efficient" motor would never be paid off with zero energy savings).

[d] $0=$ the purchase cost of the "most efficient" motor is less than that of the "less efficient" motor. In this instance, the most efficient motor is automatically more cost efficient than the less efficient motor, and the discounted payback period is equal to 0 years.

[e] $>60=$ The discounted payback period would be in excess of 60 years.

\section{RESULTS AND DisCUSSIONS}

For irrigators that can still purchase energy efficient VHS motors, our results showed some interesting trends. For energy efficient motors, in the $37-56 \mathrm{~kW}(50-75 \mathrm{hp})$ range, a premium efficient motor is preferable to an energy efficient motor. These motors are priced between standard and premium efficiency and the efficiency gain is enough to offset the cost. However, for the $75 \mathrm{~kW}(100 \mathrm{hp})$ and larger motors it is preferable to purchase an energy efficient motor over a premium efficient motor. This is also true for the $7-30 \mathrm{~kW}$ $(10-40 \mathrm{hp})$ motors, because the payback is longer than the motor life and the NPV is infinity and thus the additional cost of the premium could never be recovered by energy savings.

For irrigators who have been purchasing or who can still purchase a standard efficiency motor, it would be advantageous to purchase premium efficient motors over standard efficient motors between 7-56 kW (10-75 hp). For all of these motor sizes, the NPV is a positive value and the payback period is less than the life of the motor. However, for motors larger than $75 \mathrm{~kW}(100 \mathrm{hp})$ it is preferable to purchase a standard efficient motor.

The regulation requirement increasing the efficiency rating of VHS motors by DOE should result in savings for irrigators for new VHS motors between 7 and $56 \mathrm{~kW}$ (10 and
$75 \mathrm{hp}$ ) if pricing is comparable. However, for large motors $75 \mathrm{~kW}(100 \mathrm{hp})$ and larger, this increased efficiency requirement seems to have resulted in higher capital costs for new motors that cannot be recovered in energy savings. This is because the efficiency difference between a standard and premium efficient motor is not very different and the capital cost difference is large (tables 1 and 5).

\section{Premium EFFiCIENT Motor OR REWIND AND REbUILD}

The decision to purchase a new premium efficient motor versus rewinding or rebuilding an existing standard efficiency motor will be a decision faced by all irrigators as a result of the DOE rule. It is difficult to know the loss of efficiency that one can expect on a rebuilt VHS motor. The $0.5 \%$ to $2 \%$ loss range is probably the most likely range of loss in efficiency that may be expected by irrigators. If an irrigator can obtain a rewind that is "as good as new", it is always preferable to rewind and rebuild rather than purchase a premium efficient motor. This is accurate if the efficiency of the original motor is the same or higher than the standard efficiency assumed in this analysis for each respective motor size.

The reliability of the rebuilt motor must also be considered along with the motor's NPV and payback period. If an irrigator has a pump with critical motor failure occurring during the growing season, then the increased capital cost of a new motor may be more than offset by the risk of a rebuilt motor with uncertain workmanship. So NPV and payback

Table 5. Nominal nameplate motor efficiencies of US motors VHS motors used in this analysis.

\begin{tabular}{|c|c|c|c|c|c|c|c|c|c|}
\hline Type of Motor & $\begin{array}{l}10 \mathrm{hp} \\
7 \mathrm{~kW}\end{array}$ & $\begin{array}{l}20 \mathrm{hp} \\
12 \mathrm{~kW}\end{array}$ & $\begin{array}{c}30 \mathrm{hp} \\
22 \mathrm{~kW}\end{array}$ & $\begin{array}{l}40 \mathrm{hp} \\
30 \mathrm{~kW}\end{array}$ & $\begin{array}{l}50 \mathrm{hp} \\
37 \mathrm{~kW}\end{array}$ & $\begin{array}{l}60 \mathrm{hp} \\
45 \mathrm{~kW}\end{array}$ & $\begin{array}{l}75 \mathrm{hp} \\
56 \mathrm{~kW}\end{array}$ & $\begin{array}{l}100 \mathrm{hp} \\
75 \mathrm{~kW}\end{array}$ & $\begin{array}{l}200 \mathrm{hp} \\
149 \mathrm{~kW}\end{array}$ \\
\hline Premium efficiency & $\mathrm{na}^{[\mathrm{a}]}$ & 92.40 & 92.40 & 94.10 & 94.50 & 95.00 & 95.00 & 94.50 & 95.40 \\
\hline Energy efficient & 91.00 & na & 93.60 & 93.60 & 93.60 & 93.60 & 94.10 & 94.50 & 95.40 \\
\hline Standard efficiency & 87.50 & 89.50 & 90.20 & 89.50 & 90.20 & 90.20 & 91.70 & 93.00 & 94.10 \\
\hline Rewind (zero loss) & 87.50 & 89.50 & 90.20 & 89.50 & 90.20 & 90.20 & 91.70 & 93.00 & 94.10 \\
\hline Rewind $(0.5 \%$ loss $)$ & 87.06 & 89.05 & 89.75 & 89.05 & 89.75 & 89.75 & 91.24 & 92.54 & 93.63 \\
\hline Rewind ( $1 \%$ loss) & 86.63 & 88.61 & 89.30 & 88.61 & 89.30 & 89.30 & 90.78 & 92.07 & 93.16 \\
\hline Rewind ( $2 \%$ loss) & 85.75 & 87.71 & 88.40 & 87.71 & 88.40 & 88.40 & 89.87 & 91.14 & 92.22 \\
\hline Rewind ( $3 \%$ loss) & 84.88 & 86.82 & 87.49 & 86.82 & 87.49 & 87.49 & 88.95 & 90.21 & 91.28 \\
\hline Rewind (4\% loss) & 84.00 & 85.92 & 86.59 & 85.92 & 86.59 & 86.59 & 88.03 & 89.28 & 90.34 \\
\hline Rewind ( $5 \%$ loss) & 83.13 & 85.03 & 85.69 & 85.03 & 85.69 & 85.69 & 87.12 & 88.35 & 89.40 \\
\hline
\end{tabular}

[a] $\mathrm{na}=$ motor type not available for the particular horsepower rating. 
period tables (tables 3 and 4) could be used to assess the additional cost premium for this added reliability since these tables incorporate the operating cost. For example, a $30 \mathrm{~kW}$ (40 hp) motor with a $0.5 \%$ loss has a $-\$ 348$ NPV in table 3, so the irrigator is paying another $\$ 348$ over the life of the motor to have a new premium efficient motor versus a rebuilt motor.

When a motor is rewound the winding, bearings, and insulation are replaced. The stator core iron is reused. If the same size and quality of bearing, wire and insulation is used to rebuild the motor, then there should be some confidence that the motor will perform near its new condition so long as the core loss has not changed. Unfortunately, it is hard for the customer of a rewound motor to verify these things. The authors recommend that irrigators ask about core loss testing, if this is not done, then the loss of efficiency could be highly variable. If this is done, then losses will be attributed to the new materials and practices to rebuild the motor. They can also ask if their rebuild and rewind shop follows the EASA AR100-215 Recommended Practice for the Repair of Rotating Electrical Apparatus. If core loss testing is done, then the authors believe that the literature supports less than $2 \%$ losses and if the shop follows AR100-2015 and replaces bearings but may not monitor their burn out temperature, then $0.5 \%-1 \%$ would be a reasonable loss to expect. For shops that do not perform core loss testing, the authors assumed the losses may be in the $2 \%-5 \%$ range. Based on the recommendations in EASA AR100-2015, the key practices of controlling the stripping process and keeping their burnout temperature to below $350^{\circ} \mathrm{C}$, the authors assume that efficiency will be as good as new (zero loss).

Irrigators should also ask if bearings are replaced or reused and if any components are tested before they are reassembled. Some shops offer bearing replacement as an option, but if a motor has undergone a long service interval, it is believed that this component should be replaced, as this is likely a very neglected maintenance item on VHS motors used in agriculture.

It is hard to be decisive when considering rewinding and rebuilding because it is difficult to quantify the loss of efficiency in VHS motors used for irrigation. Thus, this analysis is much more subjective and the expected outcome is entirely dependent on the quality of the rebuild and resulting efficiency.

Another consideration is the nameplate efficiency of the motor to be rebuilt/rewound. In our analysis, it was assumed that the efficiency of the motor to be rebuilt was the same as a US Motors standard efficiency motor. However, nameplate motor efficiencies vary by manufacturer. Also, the efficiency standards vary by the date of manufacturer and what was the minimum standard efficiency of that time period. Thus, a motor that had a nominal nameplate efficiency of $1 \%$ less than the standard efficiency listed in this article, the loss category of $1 \%$ should be used for that motor. For example, in our analysis for a particular motor size, we used $90.2 \%$ as the definition of standard efficiency for a $37 \mathrm{~kW}(50 \mathrm{hp}) \mathrm{mo}-$ tor, but if the motor nameplate efficiency of the motor to be rebuilt was different, say $89.2 \%$, then the motor would only be expected, if rewound as good as new to be $89.2 \%$. Thus it may still be advantageous for the irrigator to replace the motor than have it rebuilt even if a high quality rebuild could be expected. This is the case with the $37 \mathrm{~kW}(50 \mathrm{hp})$ motor in our analysis because the payback period is less than the expected life of the motor and the NPV is $\$ 238$. It would be advantageous for the irrigator to replace the motor with a premium efficient motor than to rewind the older less efficient motor.

In summary, the small motor sizes 7-22 $\mathrm{kW}(10-30 \mathrm{hp})$ and large motors $75-149 \mathrm{~kW}(100-200 \mathrm{hp})$ are good candidates for rebuilding and rewinding so long as shops are core testing and following most of the good practices in rewinding such as replacing wire, insulation and bearings with parts equivalent to when the motor was new and the efficiency of the motor to be rewound or rebuilt is very near the efficiency we used in our analysis for standard efficiency. These motors can withstand some loss in efficiency before the NPV of the premium efficient motor becomes positive. However, in the mid-size motors $30-56 \mathrm{~kW}(40-75 \mathrm{hp})$ there is large gain in efficiency between a standard efficient motor and premium efficient motor, and in this size range, replacing these motors may be a more certain option to ensure energy efficiency savings even in situations where a high quality rewind/rebuild can be assured. For the $45 \mathrm{~kW}(60 \mathrm{hp})$ motor size, the NPV is negative for choosing the premium efficiency motor over a rewind motor only in the instance when there is zero efficiency loss for the rewind motor. If there is any efficiency loss for the rewind motor, the NPV of choosing the premium efficient motor over a rewind motor is positive for the $45 \mathrm{~kW}$ (60 hp) motor size. Thus, in our opinion, unless a certified shop rewinds this motor, it should be replaced with a premium efficiency motor. Table 6 summarizes the threshold where NPV is positive and DPP is less than the life of the motor.

\section{CONCLUSION}

This study evaluated the benefits of premium efficient motors versus standard, energy efficient and rewind/rebuilding motors. Some general recommendations about VHS motors used in irrigation were discovered.

It appears that the new DOE regulations will have a positive impact for irrigators using VHS motors in the $7-56 \mathrm{~kW}$ (10-75 hp) size, but will result in higher capital costs for motors $75-149 \mathrm{~kW}(100-200 \mathrm{hp})$ in size with no benefit to recover the additional cost through energy savings. If the motor price structure of new motors is similar to this analysis, then irrigators should consider new motor purchases for

Table 6. Acceptable loss of nameplate motor efficiency before NPV and DPP in favor of premium efficiency motors.

\begin{tabular}{ccc}
\hline $\begin{array}{c}\text { Motor Size } \\
(\mathrm{kW} / \mathrm{hp})\end{array}$ & $\begin{array}{c}\text { Acceptable Level of Loss for Rewind } \\
\text { Motor before Premium NPV is Positive } \\
\text { and Discounted Payback is Less }\end{array}$ & $\begin{array}{c}\text { Authors } \\
\text { Suggestion }\end{array}$ \\
\hline $7 / 10$ & $2 \%$ & Neutral \\
$12 / 20$ & $4 \%$ & Rewind \\
$22 / 30$ & $4 \%$ & Rewind \\
$30 / 40$ & $1 \%$ & Buy premium \\
$37 / 50$ & $1 \%$ & Buy premium \\
$45 / 60$ & $0.5 \%$ & Buy premium \\
$56 / 75$ & $2 \%$ & Neutral \\
$75 / 100$ & $4 \%$ & Rewind \\
$149 / 200$ & $4 \%$ & Rewind \\
\hline
\end{tabular}


$7 \mathrm{~kW}(10 \mathrm{hp}), 30-56 \mathrm{~kW}(40-75 \mathrm{hp})$ and rebuild and rewind for motors 12-22 kW (20-30 hp) and 75-149 kW (100$200 \mathrm{hp}$ ) in size (table 6).

For those considering rewinding or rebuilding a motor versus purchasing a premium efficient motor, it was found that for the small motor sizes [7-22 kW (10-30 hp)] and large motors [75-149 $\mathrm{kW}(100-200 \mathrm{hp})]$ rebuilding and rewinding is more feasible, so long as shops are core testing and following most of the good practices in rewinding such as replacing wire, insulation, and bearings with parts equivalent to when the motor was new and the efficiency of the motor to be rewound or rebuilt is very near the efficiency we used in our analysis for standard efficiency. These motors can withstand some loss in efficiency before the NPV and payback periods become positive. However, in the mid-size motors $30-56 \mathrm{~kW}(40-75 \mathrm{hp})$ there is large gain in efficiency between a standard efficient motor and premium efficient motor and in this size range replacing these motors may be the best way to ensure energy efficiency savings. For the $45 \mathrm{~kW}$ (60 hp) motor size, only a zero loss was acceptable to rewind, thus in our opinion, unless a certified shop rewinds this motor, it should be replaced with a premium efficient motor.

To judge how much efficiency loss could be experienced, the authors recommend that irrigators ask about core loss testing, temperature controls on burnout, resistance testing, and matching the wire size, insulation, bearing type and quality and pattern for their motor model and manufacturer. They should determine if their rebuild and rewind shop follows the EASA AR100-215 Recommended Practice for the Repair of Rotating Electrical Apparatus, if so, a good rewind/rebuild can be expected. From these simple questions, one can gain some perspective on the quality of work that they may be receiving and thus use a quality of rewind in the decision matrix that is representative. If efficiency reductions of more than $4 \%$ from standard efficiency motor nameplates used in this analysis is expected, such as would be the case if core loss was not performed, then a premium efficient motor is always more cost effective than rebuilding.

\section{REFERENCES}

Arkansas Natural Resources Commission. (2014). Arkansas Water Plan 2014 Update Appendix C Water Availability Report.

Retrieved from

http://arkansaswaterplan.org/plan/ArkansasWaterPlan/2014AW

PWaterPlan/App\%20C_Water\%20Availability\%20Report_Fina 1_11.24.14.pdf
EASA. (2003). The effect of repair/rewinding on motor efficiency: EASEA/AEMT rewind study and good practice to maintain motor efficiency. St. Louis, MO and York, England: Electrical Apparatus Service Assoc., Assoc. of Electrical and Mechanical Trades.

EASA. (2015). Recommended practice for the repair and rotating electrical apparatus. EASA AR100-2015. St. Louis, MO: Electrical Apparatus Service Association.

Gustafson, R. J., \& Morgan, M. T. (2004). Fundamentals of electricity for agriculture. St. Joseph, MI: ASAE. https://doi.org/10.13031/fea.2013

Henry, C. G., Hirsh, S. L., Anders, M. M., Vories, E. D., Reba, M. L., Watkins, K. B., \& Hardke, J. T. (2016). Annual irrigation water use for Arkansas rice production. J. Irrig. Drain. Eng., 142(11), 05016006. https://doi.org/10.1061/(ASCE)IR.19434774.0001068

Lowe, M., Golini, R., Gereffi, G., Ahmed, G., \& Tokuoka, S. (2010). U.S. Adoption of high-efficiency motors and drives: Lessons learned. Durham, NC: Center on Globalization. Governance \& Competitiveness, Duke University.

McCoy, G. A., \& Douglass, J. G. (2014). Premium efficiency motor selection and application guide: A handbook for industry (No. DOE/GO-102014-4107). Pullman: Washington State University Energy Program.

McDougall, W. (2015). A pump monitoring approach to irrigation pumping plant performance testing. MS thesis. Fayetteville: Department of Biological and Agricultural Engineering. University of Arkansas.

Montgomery, D. (1989). Testing rewinds to avoid motor efficiency degradation. Energy Eng., 86(3), 24-40.

Nadel, S., Elliott, R. N., Shepard, M., Greenberg, S., Katz, G., \& De Almeida, A. T. (2002). Energy efficient motor systems: A handbook on technology (2nd ed.). Washington, DC: United States: American Council for an Energy-Efficient Economy.

NIDEC. (2013). Modified vertical motors, industrial motors and systems. Bull. PB500. St. Louis, MO: NIDEC Motor Corp.

NIDEC. (2015). Holloshaft motors for new DOE Standards. VHS DOE XREF 12/15. St. Louis, MO: NIDEC Motor Corp.

Sahni, S., Boustani, A., Gutowski, T., \& Graves, S. (2010). Electric motor remanufacturing and energy savings. MITEI-1, January, 1-31.

Saidur, R., Rahim, N. A., Masjuki, H. H., Mekhilef, S., Ping, H. W., \& Jamaluddin, M. F. (2009). End-use energy analysis in the Malaysian industrial sector. Energy, 34(2), 153-158. https://doi.org/10.1016/j.energy.2008.11.004

USDA. (2012). Census of agriculture, farm and ranch irrigation survey. Vol. 3, Special Studies, Part 1. Washington, DC: USDA, NASS. Retrieved from http://www.agcensus.usda.gov/Publications/2012/Online_Resou rces/Farm_and_Ranch_Irrigation_Survey/

US DOE. (2016). Energy conservation program: Energy conservation standards for commercial and industrial electric motors. Final rule. Washington, DC: U.S. Department of Energy, Energy Efficiency and Renewable Energy Office (EERE). Retrieved from https://www.regulations.gov/document?D=EERE-2010-BTSTD-0027-0117 